Revista Eletrônica do Mestrado em Educação Ambienta1

Revista do PPGEA/FURG-RS

ISSN $1517-1256$

Programa de Pós-Graduação em Educação Ambiental

\title{
Ecologia como uma sinfonia da vida, das vozes do semiárido ao pertencimento planetário: uma rede conectada de sujeitos
}

\author{
Marinalva Valdevino dos Santos ${ }^{1}$ \\ Universidade Federal de Campina Grande \\ ORCID: https://orcid.org/0000-0001-5978-3474 \\ Joedla Rodrigues de Lima² \\ Universidade Federal de Campina Grande \\ ORCID: https://orcid.org/0000-0001-6617-2858
}

\begin{abstract}
Resumo: Reconhecendo a importância dos saberes tradicionais para a sociobiodiversidade, esta pesquisa tem como objetivo descrever as práticas identificadas a partir do Estágio Interdisciplinar de Vivência (EIV) e relacionar as experiências de histórias de vida oral de agricultores familiares no Sertão Paraibano com a ecologia profunda e noção de pertencimento à Terra. A metodologia utilizada foi qualitativa, realizada por meio de observação direta das práticas cotidianas, em que se observou que as atividades de reciclagem, reuso, cuidados com o manejo correto da terra, da adubação orgânica e uso de defensivos naturais e da criação animal ecológica foram mitigadoras de impactos ambientais e representam relações de responsabilidade ambiental. Com os relatos de história de vida, percebeu-se o sentimento de pertencimento à Terra e à realidade semiárida, configurando uma reestruturação do modo de vida dos sujeitos que vivem na região estudada.
\end{abstract}

Palavras-chave: Identidade terrena; Partilha de saberes; Ecologia integral.

\section{La ecología como sinfonía de la vida, de las voces del semiárido a la pertenencia planetaria: una red conectada de sujetos}

Resumen: Reconociendo la importancia del conocimiento tradicional para la sociobiodiversidad, esta investigación tiene como objetivo describir las prácticas identificadas a partir de la Pasantía Interdisciplinaria de Experiencia (EIV), y relacionar las experiencias de historias de vida oral de agricultores familiares en el Sertão Paraibano, con la ecología profunda y noción de pertenencia a la Tierra. La metodología utilizada fue cualitativa, realizada a través de la observación directa de

\footnotetext{
${ }^{1}$ Mestre em Ciências Florestais pela Universidade Federal de Campina (UFCG). Especialista em Educação Ambiental pelas Faculdades Integradas de Patos (FIP). Graduada no Curso de Licenciatura em Ciências Biológicas pela Universidade Federal de Campina Grande (UFCG). E-mail: marinalvaldevino@ gmail.com

2 Doutorado em Planejamento de Sistemas Energéticos pela Universidade Estadual de Campinas (2004). E-mail: joedlalima@yahoo.com.br
} 
las actividades diarias, donde se observó que las actividades de reciclaje, reutilización, cuidado con el correcto manejo del terreno, fertilización orgánica y uso de plaguicidas naturales, y de la ganadería ecológica están mitigando los impactos ambientales y representan relaciones de responsabilidad ambiental. Con los relatos de historia de vida se percibió el sentimiento de pertenencia a la Tierra y la realidad semiárida, configurando una reestructuración del modo de vida de los sujetos que habitan en la región estudiada.

Palabras clave: Identidad terrenal; Intercambio de conocimientos; Ecología integral.

\title{
Ecology as a symphony of life, from the voices of the semiarid to planetary belonging: a connected network of subjects
}

\begin{abstract}
Recognizing the importance of traditional knowledge for socio-biodiversity, this research aims to describe the practices identified from the Interdisciplinary Experience Stage (EIV), and to relate the experiences of oral life stories of family farmers in the Sertão Paraibano, with the deep ecology and notion of belonging to Earth. The methodology used was qualitative, carried out through direct observation of daily activities, where it was observed that the activities of recycling, reuse, care with the correct management of the land, organic fertilization and use of natural pesticides, and of ecological animal husbandry were mitigating environmental impacts and represent relations of environmental responsibility. With the life history reports, the feeling of belonging to the Earth and the semi-arid reality was perceived, configuring a restructuring of the way of life of the subjects who live in the studied region.
\end{abstract}

Key words: Earthly identity; Knowledge sharing; Integral ecology.

\section{Introdução}

Os processos de mudança de paradigmas ambientais se configuram uma necessidade emergente e envolvem a tomada de consciência sobre a relação da naturezahumanidade. Essa mudança necessita do abandono de atitudes egocêntricas, pois, através de tais condutas, a própria humanidade desconsidera os prejuízos da ausência de um pensamento que reconheça sua Identidade Terrena e sua conexão com a Mãe Terra.

Essa discussão não é recente, nem tampouco fácil de resolver, mas precisamos abrir um campo de discussão e reflexão sobre os diferentes aspectos e dimensões que o tema incorpora. Por isso, faz-se necessária a mudança para uma nova consciência, que introduza um novo olhar para as ciências de um modo geral e também para a forma como as sociedades estão estruturadas; por consequência, que mude a conduta de apropriação dos recursos naturais como se fossem fontes inesgotáveis de consumo.

A mudança paradigmática ora proposta requer o reconhecimento do vínculo profundo entre ser humano com todos os elementos da natureza, inclusive $\mathrm{o}$ reconhecimento do sentido de pertencimento à Terra, vista como um organismo vivo e autorregulado e interdependente (BOFF, 1999). Estas características integram o pensamento do filósofo francês Edgar Morin, que estruturou uma discussão em torno dos conceitos de identidade terrena ou planetária, considerou necessário entender a 
complexidade da crise planetária, que é marcante no século $\mathrm{XX}$, e apontou para o destino comum de todos os seres que agora estão diante das mesmas problemáticas, sejam nas esferas limitantes de vida ou de morte (MORIN, 2000).

Nesta identificação, o sujeito reconhece-se integrado e, portanto, interdependente da Terra-viva (Gaia), pois “O ser humano é natureza que se torna consciente" (PORTOGONÇALVES, 2006). Essa consideração molda sua existência, seus atos, suas escolhas e seus valores.

Evocando um pensamento policêntrico, que é alimentado por diferentes culturas do mundo, Morin (2000, p. 65) propõe: "Educar para este pensamento é a finalidade da educação do futuro, que deve trabalhar na era planetária, para a identidade e a consciência terrenas". Esse pensamento policêntrico estruturará novas epistemologias, que percorrerá os caminhos da religação, permutando da separação/fragmentação para a "simbiosofia", que é a sabedoria de viver junto" (MORIN, 2000, p.78).

Este trabalho parte da premissa de que os desafios socioambientais pós-modernos exigem uma mudança paradigmática complexa, no sentido de conectar sujeitos e saberes para o resgate da identidade terrena dentro do entendimento ecológico multidimensional, que faz o homem reconhecer outras dimensões ou realidades da natureza, o que o inclui como elo interligado e implicado nesse processo.

A base de leitura desta identidade se ancora no resgate dos saberes da tradição, nutrido pela experiência sensível dos sujeitos com os saberes da natureza. Este saber é incorporado pela humanidade e condiciona uma "nuvem carregada de ecologia das ideias" repassadas entre as gerações, sendo um conjunto de conhecimentos ancestrais que um povo possui, regressando aos seus descendentes através de sua experiência e leitura de mundo (ALMEIDA, 2017).

Dessa forma, esta pesquisa resgata os saberes tradicionais dos agricultores familiares da região semiárida no Sertão Paraibano. Sob o viés de uma discussão científica não somente focada nas questões ambientais, mas com um olhar investigativo que estrutura o pensamento e liga o homem à natureza da qual faz parte. $\mathrm{O}$ não entendimento dessa estruturação implica um obstáculo epistemológico na tomada de consciência da identidade terrena e planetária (MORIN, 2015).

Reconhecendo a importância dos saberes tradicionais para a sociobidiversidade, esta pesquisa tem como objetivo descrever as práticas identificadas a partir do Estágio Interdisciplinar de Vivência (EIV) e relacionar as experiências de histórias de vida oral de agricultores familiares no Sertão Paraibano com a ecologia profunda e a noção de 
pertencimento à Terra. Portanto, esta pesquisa se configura uma experiência técnica de campo e contribui para tornar visíveis as vivências dos agricultores familiares no semiárido em relação as suas responsabilidades socioambientais.

\section{Metodologia}

A pesquisa é produto de uma metodologia qualitativa, por meio da observação direta com uso de Estágio Interdisciplinar de Vivência (EIV), que se constitui um método de imersão e observação ativa do pesquisador no ambiente pesquisado para obter maior número de informações que podem ser captadas no ambiente em que se realiza o estudo (FEAB, 2005).

O estudo foi realizado no período de 10 a 17 de Junho de 2019, em uma propriedade de agricultores familiares, no Município de Cacimbas, no Estado da Paraíba, Nordeste do Brasil. A pesquisa obteve aprovação do Comitê de Ética (CEP)/ Número do Parecer: 3.327.816, em 15 de maio de 2019, com a permissão dos participantes envolvidos através de Termo de Consentimento Livre e Esclarecido.

Nesta metodologia, estabelece-se um elo de convivência cotidiana, sendo eficaz ao entendimento das relações dos sujeitos, como atores socioambientais e na sua influência na sociobiodiversidade. A pesquisadora passou a conviver com a família integralmente desde o primeiro dia da chegada ao sítio, acompanhando atividades, dormindo na residência, acompanhando a rotina de trabalho, refeições, durante os sete dias. A postura adotada foi de observadora da rotina diária da família, mesclada ao envolvimento nas atividades da experiência diária. Pela observação direta, foi possível descrever e entender a dinâmica das relações socioambientais.

A observação ativa ou direta pode ser formal ou informal e fornece uma fonte de ações observáveis para entendimento da dinâmica social (YIN, 2005). No EIV, a observação ativa se estabelece ao longo de dias programados, e o pesquisador (a) se insere integralmente na dinâmica da família, abrindo espaço para as percepções em relação ao não dito pelos agricultores familiares ou às informações que muitas vezes são vividas, mas que eles não conseguem explicar.

Algumas etapas antecederam a realização do EIV: uma prévia fundamentação teórica para o entendimento da dinâmica ecológica local em torno desse campo de ideias e vivências; subsequentemente, buscou-se um meio de aproximação com as famílias que desenvolvem práticas agrossilviculturais. 
Nesta fase, a ONG CEPFS (Centro de Educação e Formação Popular do Semiárido), dentro do espaço geográfico que atua, auxiliou na aproximação da pesquisadora com um núcleo de agricultores familiares, composto por 6 pessoas - o casal, 2 filhos e 2 netos na propriedade localizada no Sítio Lagoa de Campo, localizado no Município de Cacimbas, Paraíba. Eles cultivam frutíferas, hortaliças, plantas ornamentais e medicinais, incluindo a criação de galinhas e caprinos. Após a etapa da vivência, as informações e percepções da pesquisadora foram organizadas e apresentadas em forma de resultados, discussões e conclusões.

\section{Resultados e Discussão}

Os resultados e discussões estão organizados em três blocos: (1) As experiências do grupo familiar pesquisado e relato técnico, (2) Fundamentação teórica/científica sobre Experiência, Pensamento e Realidade; sobre o saber da tradição, da ciência e da ecologia profunda e (3) Narrativa do Estágio Interdisciplinar de Vivência.

\section{1- As experiências do grupo familiar pesquisado e relato técnico}

Em relação à agricultura familiar, a experiência envolveu uma unidade de produção que realiza prática agroecológica sertaneja em ambiente semiárido. Nesta região, as famílias enfrentam longos períodos de estiagem e desenvolvem formas para conviver com esta realidade. Os solos são férteis, porém rasos e pedregosos, que não absorvem muita água, escoando o recurso que é escasso na região (AGUIAR et al., 2006) e, embora o clima se configure como quente e seco, com chuvas irregulares, o manejo adequado viabiliza as práticas agrícolas de silvicultura e olericultura no ambiente.

$\mathrm{O}$ acesso às políticas públicas, incluindo também o acesso aos direitos básicos à saúde, segurança e educação, para este setor ainda é deficiente, sendo minimizado pela atuação das associações rurais, que funcionam como catalisadores das informações até os produtores de unidades familiares e utilizam métodos participativos como ferramenta de sensibilização destes produtores rurais (BAPTISTA; CAMPOS, 2013). Na comunidade estudada, pode-se perceber, através dos relatos, que o mesmo cenário de precariedade se repete, pois, os sujeitos da comunidade necessitam se deslocar a outros municípios para obterem atendimento de políticas públicas básicas.

O sustento familiar é retirado do trabalho nas terras onde residem, fazendo uso da terra através do plantio de hortaliças, frutíferas, plantas medicinais e grãos, que se mesclam 
à criação de animais. A maioria das atividades são realizadas no turno matutino, devido à forte incidência solar no período da tarde. A família obtém renda durante todo o ano, devido ao cultivo diversificado e pelas diferentes formas de uso da terra.

A experiência em evidência para essa pesquisa sobreveio de um conjunto sistematizado de ideias, vivências, análises e observações in loco. A chegada à propriedade foi acompanhada por agentes da ONG CEPFS, que facilitou o contato com a família. O perfil de faixa etária dos agricultores é de 50-55 anos que residem na propriedade há cerca de 35 anos e adquiriram a terra por divisão de herança. A propriedade tem 15 hectares e a divisão resultou em lotes com até 3 ha, correspondendo a área que desenvolve as práticas agropecuárias e silviculturais.

Na composição estrutural da propriedade, pode-se destacar um pequeno barreiro (açude), um galinheiro improvisado, uma área plantada com cultivo diversificado, cercados para a criação de bovinos-ovinos, três cisternas. A propriedade mantém uma área de preservação ambiental. Existe também um depósito ao lado da residência, onde armazena a colheita e as sementes que servirão para os próximos plantios (Figura 1).

Figura 1. Residência de agricultores familiares onde foi realizado o estágio de vivência. Sítio Lagoa de Campo, Município de Cacimbas/PB; vista frontal do depósito e as sementes armazenadas em garrafas PET.

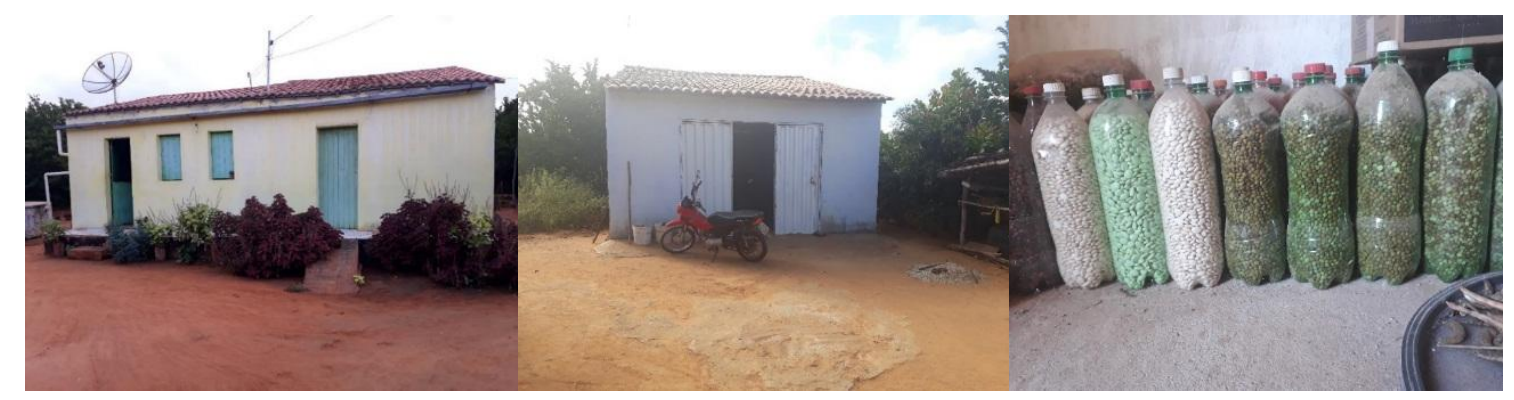

Fonte: Dados da pesquisa (2019).

Importante destacar que a preservação das sementes tanto ajuda na conservação da biodiversidade de cultivos e no fortalecimento do potencial genético das espécies nativas da região, quanto proporciona autonomia ao produtor ao possuir as sementes para o próximo plantio, inclusive, diminuindo os custos de sua produção, que é um fator essencial para estas famílias.

Quanto à fruticultura, há uma maior diversidade em comparação às outras espécies cultivadas de ciclo curto. Na propriedade, são cultivados, utilizando o termo vulgar: limão, pinha, banana, seriguela, manga, romã, condessa, abacaxi, morango, umbu, goiaba, mamão e laranja. E as culturas de ciclo curto são pimenta, pimentão, feijão/fava, 
milho, macaxeira, alface, tomate, quiabo, coentro, couve-flor, rúcula, abóbora, pepino, cebolinha, urucum e plantas medicinais. Também produzem proteína animal a partir da criação de caprinos, ovinos, aves e bovinos. Considerando a segurança alimentar, a produção destina-se primeiro para o consumo familiar; o excedente é comercializado em feiras ou na própria residência.

Quanto à forma de utilização dos recursos naturais e os cuidados com o meio ambiente, elencamos as seguintes práticas identificadas durante o EVA: Utilização de um defensivo natural, utilizado para repelir pragas que interferem no desenvolvimento do plantio. Este defensivo é produzido pela própria família, à base de alho, sabão e cinza; o sabão utilizado nas atividades domésticas também é artesanal, fabricado com óleo reaproveitado, soda cáustica e amaciante.

A serrapilheira, que é retirada do terreiro próximo a casa, é utilizada como cobertura morta. Essa técnica de reuso foi apreendida nas oficinas da ONG. Antes, a prática era de juntar e queimar como se não tivesse uma utilidade. As garrafas PET são utilizadas de diversas formas, uma delas é para o armazenamento de água a ser usada na época de estiagem. No período de armazenamento, elas desempenham uma função decorativa na ornamentação do jardim (Figura 2 A e B).

Figura 2. Uso da serrapilheira como adubo de solo (A) e uso de garrafas PET na ornamentação do jardim (B).

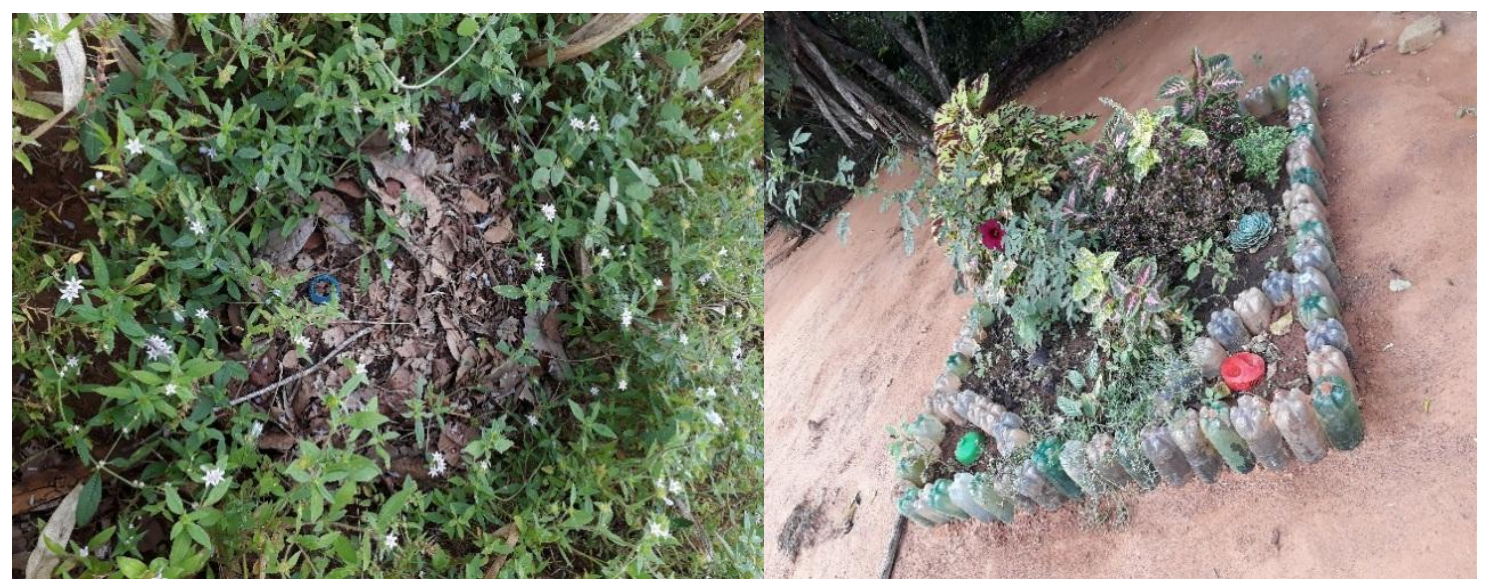

Fonte: Dados da pesquisa (2019).

Importante considerar que, mesmo com a existência de práticas agroflorestais, tais esforços seriam insustentáveis ambientalmente se não fosse incentivado o sentimento de comunidade e coletividade. Eles reconhecem que todo avanço nas atuais práticas de vivência no semiárido se devem à atuação das ONG's locais e ao papel aglutinador e disseminador realizado pela Central das Associações de Cacimbas (CAMEC). 
Relataram que a associação da comunidade foi fundada há 21 anos, e a sede é própria, onde acontecem as reuniões, "atualmente apenas 20 participantes são assíduos e associados"3. O agricultor ressalta a importância desta associação: "Serve para gente saber das coisas que é de interesse de todo mundo da comunidade”.

O Programa "Um milhão de Cisternas" do governo federal foi prioritariamente disseminado pelo PROPAC (Programa de Promoção e Ação Comunitária) que viabilizou tanto a construção das cisternas para as escolas da comunidade quanto para cada propriedade, inegavelmente melhorando o acesso ao recurso limitante da água e, consequentemente, a qualidade de vida dos sujeitos do semiárido. Como relata o agricultor: "Melhorou bastante, principalmente com as cisternas, porque temos onde guardar água e temos água o ano todo, podemos produzir e colher para comer e se sobrar a gente vende na feira".

O primeiro auxílio que obtiveram foram por meio do Programa "Luz para Todos", do governo federal, que lhes deu acesso à energia elétrica e, posteriormente, o programa de cisternas. O agricultor relata como era a vida sem essas duas tecnologias sociais e que isso refletia nas difíceis condições que comprometiam a qualidade de vida e no bem-estar da família: “Antes a gente usava lampião, vivia no escuro, e para ter água tinha que andar muito em busca de um poço que ficava distante daqui e era uma alegria quando conseguia trazer um galãozinho d'água, e era para beber não era para outra coisa não".

Antes do advento das cisternas, o cultivo não era diversificado e se plantavam apenas uma ou duas culturas anuais. A agricultora relata: "Não tinha como plantar muita coisa, era só cajueiro e pinha, porque não dependem muito de água para sobreviver". Considerando a água como fator limitante à qualidade de vida e ao bem-estar desses sujeitos, houve uma mudança significava nesses atributos com as cisternas.

A rotina de trabalho acontece de forma mais intensa no período da manhã devido ao melhor conforto térmico. Neste turno, fazem a colheita, o cultivo, o armazenamento, os cuidados com a lavoura e tratos dos animais. Durante a tarde, descansam e realizam tarefas que não envolvem trabalhos com exposição ao sol. As atividades são divididas por gênero, e os afazeres domésticos ficam a cargo das mulheres, que também assumem alguns cuidados com a lavoura, atividade prioritariamente desempenhada pelos homens adultos.

A comercialização do excedente da produção, principalmente de horticultura, é realizada na própria comunidade e na feira de agricultura familiar, que acontece aos

\footnotetext{
${ }^{3}$ As frases no corpo do texto destacadas em itálico representam as narrativas de histórias de vida oral dos agricultores familiares.
} 
domingos. Nesta feira, comercializam-se alimentos in natura ou processados de forma artesanal, plantas ornamentais e medicinais e tudo aquilo que seja produzido pelas unidades familiares. Neste espaço, também compartilham vivências, experiências e as ações comunitárias são fortalecidas.

Dentre as tecnologias sociais, além das cisternas, há a horta orgânica de economia de água, o quintal produtivo, o banco de sementes e outras técnicas inovadoras que são apreendidas nas oficinas e nos intercâmbios de agricultores familiares.

Importante ressaltar que a proposta de vivência no semiárido se refaz e é fortalecida pelas tecnologias sociais, pelos modelos de economia solidária, ações de ecoturismo e ações comunitárias, a exemplo dos intercâmbios de saberes, da troca de sementes naturais, da vivência das associações, sob o foco da agroecologia.

Também se identificou que as concepções sobre a natureza, o ambiente que se vive e sobre os sujeitos do semiárido são voltadas para a revalorização e o pertencimento ao lugar que se vive, inicialmente valorizando o próprio sertanejo. Como defende Gualdez et al., (2018), fortalecendo uma sustentabilidade ambiental a longo prazo.

A área da propriedade estava degradada pelas sucessivas queimadas realizadas pelo antigo proprietário, inclusive era considerada uma área de difícil cultivo. Após a mudança nos tratos com o solo, como a incorporação de adubo orgânico e o uso de defensivos naturais na lavoura, suas características foram melhorando em relação à porosidade, à presença de matéria orgânica, possibilitando um melhor desenvolvimento do sistema radicular da planta e o armazenamento da água no solo. $\mathrm{O}$ agricultor considera que "Não existe solo ruim, existe solo que não teve os cuidados corretos", conseguindo produzir com base na agroecologia.

O modelo de produção, as tecnologias sociais e as técnicas em geral utilizadas na produção respeitam as condições edafoclimáticas do semiárido. As condições do solo, a pluviosidade e o clima são considerados, em geral, como fatores negativos. Eles se revertem a partir de técnicas adaptadas às condições do ambiente semiárido e produzem o suficiente para alimentar a família e produzir um excedente que é vendido.

Portanto, os fenômenos que envolvem as questões ambientais ocorrem de forma interligada aos fatores sociais e econômicos. Para Loureiro (2013), quando se trata da intepretação de questões que envolvem o fator “ambiente", é necessário o entendimento de que esse fator não é composto apenas de questões ecológicas/ambientais, mas deve-se integrar os fatores sociais e culturais específicos de cada localidade. 
Dessa maneira, as vivências no semiárido necessitam da incorporação das narrativas de história de vida oral para o entendimento das relações de impactos socioambientais e, a partir da compreensão da realidade das experiências vivenciadas, formular estratégias de mudanças de pensamento pautadas na conscientização ambiental.

\section{2 - Experiência, Pensamento e Realidade}

A noção de experiência aqui trabalhada está de acordo com as ideias de Morin (2015), que imputa a implicação do sujeito no conhecimento, entendendo que este, ao vivenciar experiências, está mergulhado no universo do conhecimento e não dissociado dele. Diferente do que diz a ciência moderna, o sujeito é participante ativo e influenciador das pesquisas que produz. Pela noção do físico alemão Werner Heisenberg (2009), não existe limite de separação entre observador e observado, entre sujeito e objeto, depreendendo-se dessa observação que a ciência que é construída por sujeitos humanos e abarca muito de suas subjetividades e percepções de realidade.

No estágio de vivência, a pesquisadora conseguiu mergulhar num universo que não fazia parte do seu cotidiano, o contexto dos agricultores familiares do sertão paraibano, que lidam com práticas de base agroecológica. Essa imersão nas experiências de "outros" proporcionaram um olhar diferente, que, no contexto acadêmico, não se poderia vislumbrar, mas esta metodologia de EIV abriu outra visão de mundo sobre as experiências da agricultura familiar, suas práticas cotidianas, suas expectativas e realizações, embora limitada a uma única vivência.

Adentrando nesse campo da experiência, faz-se necessária a discussão dos conceitos de modo geral, visto que nos fundamentos dos conceitos podem se esconder as confusões do pensamento, que se refletem pela historicidade dos contextos através do tempo. Para Almeida (2017), os conceitos são repletos de historicidade e não são nulos ou frios, mas carregam consigo significação de acordo com o contexto científico em que nascem. Deleuze e Guatarri (2010) fortalecem esse esclarecimento quando dizem:

Apesar de datados, assinados e batizados, os conceitos têm sua maneira de não morrer e, todavia, são submetidos a exigência de renovação, de substituição, de mutação, que dão a filosofia uma história e também uma geografia agitada, das quais cada momento, cada lugar se conservam, mas no tempo, e passam, mas fora do tempo (DELEUZE e GUATARRI, 2010, p.16).

Os conceitos são considerados como instrumentos e ferramentas cognitivas para a exploração de conhecimentos, mas nunca como fins. São meios de compreender o mundo e 
os fenômenos e, por isso, são limitados, são construções humanas (ALMEIDA, 2017). Não deveriam ser encarados como verdades absolutas, pois todo conceito é um fragmento ordenado de uma realidade marcada no tempo, mas não a interpretação real do fenômeno. A linguagem possui limitações e outros aparatos cognitivos, podem ser necessários para a compreensão da natureza.

A compreensão dos fenômenos da natureza requer que o conhecimento seja tratado como um processo de ordenação da realidade, que não é estática ou fixa, mas se expressa por meios de fenômenos em movimento, processos em fluxo. Fato que implica o sujeito através da experiência, ou seja, é integrante do conhecimento que produz ao observá-lo (BOHM, 2008).

Dessa maneira, trata-se de o conhecimento "fazer sentido" pela vertente da experiência; assim sendo, o conceito de experiência na concepção de Larrosa (2011) é “isso que me passa” (LARROSA, 2011, p.7). Para essa compreensão, o autor resgata a noção etimológica da palavra e seu sentido semântico. Seguindo essa ideia, a experiência é um processo entre o antes e devir, a ida e a volta para "supor um movimento de exteriorização, de saída de mim mesmo", que "supõe que o conhecimento afeta a mim, que produz efeitos em mim, no que eu penso, no que eu sinto, no que eu sei, no que eu quero" (LARROSA, 2011, p. 7, 8).

Pelo eixo estrutural da concepção Larrosiana de experiência, esta pesquisa encaminha-se na experiência da observação ativa com Estágio de Vivência Interdisciplinar (EVI), que, apesar de ser uma metodologia bastante disseminada na área de ciências sociais, teve seu surgimento na área das ciências agrárias, com estudantes de Agronomia inicialmente, que almejavam unir a teoria acadêmica de extensão rural à vida cotidiana, na tentativa de compreender a dinâmica social e sua relação com a agricultura e a biodiversidade local (FEAB, 2005).

A história de vida oral tem um papel fundamental nos processos que incluem uma noção de ecologia integral, pois precede e sustenta a racionalidade (VERGANE, 2002). Portanto, essa conexão entre a racionalidade e as narrativas criam as representações de mundo que a humanidade carrega em relação à natureza através das experiências vividas.

Todo o processo que se configura na experiência está conectado com as categorias de organização do pensamento humano, ou seja, a maneira de pensar do que temos consciência se reflete em todas as áreas, inclusive como pensamos sobre nós mesmos. Dessa maneira, experiência e conhecimento se transformam em um único processo, na 
forma de um atributo que age de estilos diferentes, mas são o mesmo nível de organização da natureza (BOHM, 2008).

As leituras de mundo que a humanidade possui devem ser entendidas como fluxo universal de eventos e processos (BOHM, 2008). No entanto, a busca pelo entendimento dos fenômenos levou a humanidade a um processo de divisão para se entender sobre as coisas, e o homem fragmentado criou sua própria representação de natureza desconexa, que não condiz com a natureza real.

As especialidades e fragmentações do conhecimento deveriam ter sido uma estratégia de pensamento para se compreenderem os fenômenos, no entanto se configuram a própria fragmentação da humanidade (BOHM, 2008). Sendo a natureza humana um organismo multifacetado, que abarca múltiplas leituras de mundo, não obteria proveito com o enclausuramento em partes desconexas fragmentadas de sua natureza. A realidade e sua percepção requerem ligação, conexão de saberes para que o conhecimento ordenado seja conforme sua natureza.

A realidade da natureza das coisas não se configura no isolamento, mas na interligação. Se analisarmos a etimologia da palavra realidade, iríamos perceber que realidade vem do latim "res", que significa coisa. Portanto, a natureza das coisas está ligada à noção de realidade de que temos consciência.

A noção trabalhada no instrumento do EVI para esta pesquisa tem fundamento na "realidade primária da natureza", termo esse estruturado por Bohm (2008), que o explica como sendo aquilo que não pode ser mensurado, visto que a medição trata de uma visão humana sobre a natureza e está condicionada a limitações, mas que pode ser observada através da experiência vivida. Por isso, a ideia de consciência planetária é estabelecida no campo da experiência, que implica os sujeitos na natureza e no conhecimento, o que resgata a consciência de identidade terrena (MORIN, 2015).

Essa noção de natureza é por vezes experienciada, mas não se enquadra na linguagem acadêmica, pois refere-se a um outro estilo de representação de mundo, que envereda por caminhos paralelos e pode fazer as mesmas representações por estilos diferentes.

A vida implicada na conexão da ecologia profunda, integral e multidimensional não se expressa apenas pela linguagem escrita. Essa experiência dos indivíduos com a natureza se reflete nas narrativas orais, proporcionando o sentimento de pertencimento e de implicação no lugar vivenciado. Portanto, Morin (2000) indica este processo como a noção 
de identidade terrena ou planetária, atribuindo à humanidade a sua identidade como pertencente à Terra, casa comum de todos os seres.

Sendo necessário ordenar os pensamentos na lógica do fluxo da natureza do conhecimento, para compreender a humanidade que surge do conhecimento (MORIN, 2015). A cosmologia da vida e as teias que unem a vida de forma complexa direcionam-se à união da vida no universo, onde tudo se conecta, onde tudo está ligado, mas descrever ou discutir tal conexão apenas pela lógica não é o suficiente, visto que é pertinente religar os saberes e os seres que se fragmentaram a ponto de existirem como se fossem isolados.

Nessa conjuntura, o que seria então a lógica senão um ligar de ideias na ordenação da mente humana? Seria demasiado inepto o mover da força criadora da mente baseada em uma lógica de ideias desconexas e estáticas, que mutila o fluxo da imaginação, sendo relevante conectar as ideias de Werner Heisenberg, no seu livro "A Parte e o Todo" que diz: "É um erro comum supor que tudo o que importa na ciência são a lógica, a compreensão e a aplicação de leis naturais estabelecidas. Na verdade, a imaginação desempenha um papel decisivo na ciência, sobretudo na ciência natural" (HEISENBERG, 1996, p. 218).

Contudo, a imaginação desempenha um importante papel no processo criativo na ciência e, através do reconhecimento da possibilidade de erro e de incertezas, o pensamento é para ser libertado das prisões das certezas (MORIN, 2015). A união da vida no universo, nas teias que ligam todas as coisas podem ser percebidos como um grande espetáculo universal em curso constante. O universo é muito mais que um problema a ser resolvido na urgência das nossas aspirações, configura-se um movimento real da alma universal. Portanto, experiência, realidade e pensamento são faces da mesma moeda que coexistem no fluxo da natureza conectando os saberes dos povos, das ciências e da natureza.

\subsection{O saber da tradição, o saber científico e a ecologia humana.}

A intelectualidade está ligada ao sujeito que possui inteligência. Portanto, esse conceito não é exclusivo dos ambientes acadêmicos, nem apenas dos sujeitos que frequentam esse ambiente. Nessa concepção, Almeida (2017) deu origem ao termo “intelectuais da tradição" para aqueles que leem o mundo e os fenômenos da natureza através de suas experiências. Designando a esse termo os sujeitos que, pela sua inquirição, ordenam saberes, que obedecem a um rigor, ao mesmo tempo em que garantem a sua sobrevivência em equilíbrio com natureza. 
Esta pesquisa se baseia no pressuposto de que a inteligência deve ser entendida como ato condicionado pela percepção, que se molda pela experiência. Aos saberes da tradição se somam as narrativas que são repassadas de geração a geração entre as famílias. A exemplo do relato do agricultor sobre os formigueiros:

Para se entender da natureza tem que se colocar no lugar, então eu aprendi isso com meu pai, e tive que pensar igual formiga. Observando como elas construíam os formigueiros percebi que elas não interagiam com os formigueiros de outras formigas somente naquele que elas faziam parte. Então, peguei a terra de outro formigueiro e coloquei ao redor das hortaliças que elas comiam e as formigas não ultrapassavam a linha de terra, porque entendiam que era outro território, de outro formigueiro. Assim pude resolver o problema das formigas.

Essa mesma narrativa é relatada por Silva (2015), agricultor do Rio Grande do Norte, que teve sua história de vida oral no Livro "Um sábio na natureza", quando também relata que "é preciso pensar como a natureza"; essa é uma característica e narrativa comum a alguns dos atores socioambientais do campo. Mas para "pensar como a natureza" é necessário estar imerso nela (SILVA, 2015). Ao homem que se distância e que se exclui da natureza, não é dada essa consciência de natureza como teia da vida que interliga tudo e todos.

Uma das características citadas nessa narrativa acima é a observação, a etapa inicial do método científico. Para Silva e Bonfim (2019, p. 38), “O saber tradicional é a forma mais antiga de produção de conhecimentos e nasce com a própria humanidade, este é então a mais antiga das ciências". No entanto, é notório que existe preconceito dos saberes científicos sobre os saberes tradicionais. Importante destacar que os saberes tradicionais não são senso comum; eles obedecem a um rigor de observação e de experimentação, que é teste para sua permanência na história de vida oral (ALMEIDA, 2017).

Estes saberes permitem que os intelectuais da tradição enxerguem para além de seu lugar e de seu tempo, reconfigurando suas experiências com a natureza, percebendo o mundo pela ligação de diversos saberes; são sensíveis ao potencial multimensional humano, que sente não somente através da representação pela linguagem verbal, mas pelos múltiplos sentidos e linguagens que carregam.

Finalmente, destaca-se, neste conjunto de ideias, o papel que cabe à ecologia humana que, ao estudar as comunidades tradicionais, traz luz aos problemas socioambientais vivenciados e possibilitam reflexões sobre as experiências das 
comunidades tradicionais (MARQUES, 2014). Segundo Bonfim (2016), a humanidade é dotada de características genéticas, ecológicas, sociais e ainda incluem a cultura, a política e a religião, que permutam e integram suas relações ecológicas.

Portanto, ao integrar as complexidades socioambientais a partir do conhecimento da oralidade dos povos e suas ações, a ecologia humana estrutura epistemologicamente os saberes tradicionais (MIRA et. al., 2016). Para se estabelecer o entendimento das interações que derivam do campo da ecologia humana, faz-se necessário entender que ela se estrutura sobre os pilares da conexão entre Natureza-Ser, Cultura-Meio Ambiente, Interdisciplinaridade e Emancipação Humana (BOMFIM, 2016). Esse campo das ciências tem o papel de fechar uma lacuna que antes existia na ausência dessas estruturações na ecologia clássica, considerando que ela incorpora agentes nos ecossistemas pelo estudo de suas relações e impactos causados à natureza (MARQUES, 2014). De forma que:

[...] a visão da Ecologia Humana se assemelha a uma teia onde as forças se distribuem como se fosse uma rede, na qual a ausência ou o rompimento de um único filamento gera energia excessiva sobre os demais, podendo assim, comprometer seu equilíbrio e funcionamento harmônico (ALVIM, 2012, p. 22).

A emergência da conexão de saberes se configura na necessidade da humanidade de entender sua condição planetária e seu lugar neste sistema para garantir que as futuras gerações desfrutem de uma consciência de cidadãos pertencentes a uma coletividade.

No entanto, não se trata apenas do entendimento das interações da natureza humana, mas dessa ligação com a natureza de modo geral, do entendimento das consequências e impactos causados ambientalmente, que Silva e Bonfim (2019) dispõem sobre a emergência de uma reflexão da relação entre os seres humanos - a natureza - a natureza e os seres humanos e a influência disso para o planeta, em que todos os seres colaboraram com as conexões e interações na natureza.

Portanto, os saberes científicos, tradicionais ou de uma ciência específica como a ecologia humana necessitam se direcionar para um pensamento múltiplo e conectado, que ajude a entender as problemáticas complexas do mundo atual (MORIN, 2015). Entendendo-se a importância da multiplicidade e diversidade de saberes para estruturação de novas narrativas de transformação socioambiental.

\section{3 - Narrativa da experiência de vivência}

Realizando uma conexão de saberes, evoco a memória o livro "Vidas Secas" de Graciliano Ramos (1998), pois, ao lê-lo, minha voz embragou e meu espírito projetou-se 
àquelas descrições literárias de nossos antepassados no sertão! Tristeza é o sentimento que se instala pelas narrativas e pelo olhar e escrita de Graciliano, que, ao descrevê-las, foi necessariamente cirúrgico. Ao observar e comparar a realidade do passado com a de hoje, alegro-me com as mudanças positivas e com o vislumbre que muitas outras serão necessárias.

Identifiquei outras narrativas dolorosas do sertão, que fazem parte da vida destes com quem compartilhei dias de convivência. Mas fico altiva com os relatos de esperança, de auto aceitação, de empoderamento, do resgate da autoestima do homem do campo, de sua alegria por poder estar no seu lugar, onde ele se identifica e as coisas mais simples fazem sentido. Onde homem e natureza se harmonizam, onde a integralidade das relações com a natureza não é relatada, mas vivida.

Por vezes, fiz perguntas que eles não souberam responder, mas suas práticas eram respostas sem palavras. Percebi que a linguagem muitas vezes não explica fenômenos complexos e que envolvem a totalidade da natureza. Dessa forma, a consciência de identidade terrena é de suma importância no entendimento dos demais fenômenos, uma vez que os saberes não são fragmentados, e essa noção psicológica fragmentária se estende a todas as áreas do pensamento, fazendo nascer crises de separabilidade e de desconexão com a condição humana.

Como medida de estratégia no campo educacional, Morin (2003), discute a importância de uma educação para a identidade terrena ou planetária, por acreditar que é através da educação que os sujeitos adquirem maneiras de mudar paradigmas e fazer nascer um sentimento planetário. Um dos relatos da agricultora do EIV ressaltam a visão importância da educação familiar ao dizer que "A criança, minha filha, é um disseminador da educação. Tudo que a gente ensina em casa ela leva para vida”. (Figura 3).

Figura 3. Crianças brincando no terreiro em frente à casa. Sítio Lagoa de Campo,

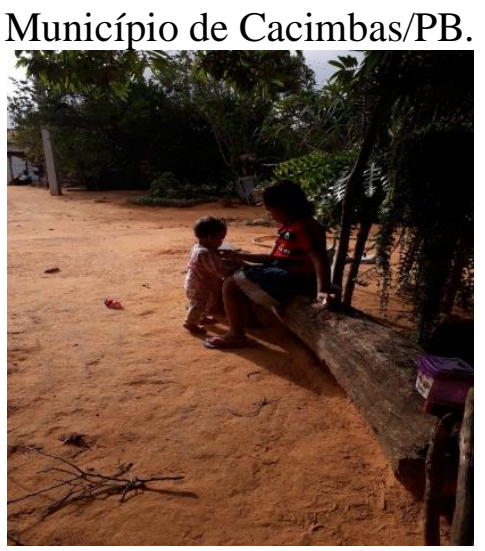

Fonte: Dados da pesquisa (2019). 
Esse relato surgiu enquanto ela cuidava da sua netinha de colo. Ao escutar tal afirmação, meus ouvidos abriram-se para essa afirmação. Mesmo não tendo a oportunidade de passar pela escola, ela faz uma leitura de mundo através da educação coletada pelas suas experiências e incorpora a importância da educação às crianças. Com o desenrolar da conversa, percebi que a educação de que falava não era a letrada, mas sim da educação dos costumes, dos valores familiares, que faziam formar o que na forma culta e formal chamamos de ética das sociedades.

Diante disso, constato que existe outra forma de educar, que não se resume à linguagem escrita. A linguagem oral é importante no processo de aprendizagem e, também, as experiências familiares, as formas de olhar os processos cotidianos; deste modo, os "iletrados" leem o mundo.

A narrativa do agricultor que diz "Temos uma farmácia a céu aberto na natureza, tem remédio para tudo", descreve a ideia de natureza como algo integral, pois ela influencia na representação em todos os outros aspectos que o homem pode perceber. Corrobora com o relato de Silva (2015), ao afirmar que "Pisamos na medicina da natureza e nem percebemos" (SILVA, 2015, p.87), indicando uma postura diferente daquela de desvalorização da natureza, o que se configura uma consciência do homem-natureza e de identidade terrena, em que os sujeitos percebem que a natureza não é apenas um recurso a ser explorado, mas estão introduzidos nela como partes integrantes da natureza.

Por isso, a noção de intelectuais da tradição aponta que esses sujeitos são peritos em observar os sinais da natureza, não havendo diferença nem de natureza nem de grau, mas de estilos/estratégias de pensar entre os saberes da tradição e os saberes científicos, que têm potencial sócio-histórico-ambiental relevante, pois a cultura científica e os saberes da tradição estruturam mentenfatos ${ }^{4}$ singulares, ou seja, manifestações do saber que incorporam a realidade (ALMEIDA, 2017).

Dessa forma, os saberes que são ordenados pelos sujeitos através da ligação de saberes obedecem ao condicionamento da incorporação de uma rede conectada de sujeitos, que possuem enraizamento planetário, e que reconhecem sua condição de natureza humana, para despertar o cuidado, o pertencimento, a identidade, e a ecologia da vida com a Mãe Terra.

\footnotetext{
${ }^{4}$ A palavra 'mentefatos' caracteriza um silogismo para caracterizar um conjunto de ideias de diferentes categorias do conhecimento, tais como as filosóficas, científicas, tradicionais, valores éticos, e ideologias, refletindo variadas manifestações do saber, que, pela força da exteriorização da diversidade, compõem a realidade, incorporando um raciocínio dedutivo entre as premissas dos saberes científicos e os saberes tradicionais para inferência de uma conexão entre estes, pela valorização de ambos e para entendimento da importância que existe na religação de saberes.
} 


\section{Considerações Finais}

Através da observação das atividades cotidianas do EIV, foi possível identificar as relações de responsabilidade ambiental através das atividades de reciclagem, reuso e cuidados com o manejo correto da terra com o emprego da adubação orgânica, uso de defensivos naturais, a criação animal a partir de princípios ecológicos e a mitigação dos impactos ambientais.

Com os relatos de história de vida oral, constatamos o sentimento de pertencimento à Terra e o respeito à realidade semiárida através do cuidado com a terra, das tarefas do dia a dia, o que os tornam "um" com o ambiente que os rodeia. Toda essa profunda consciência ecológica fruto da experiência vivida se manifesta tão naturalmente no cotidiano, que os agricultores nem sabem descrever, só vivem em harmonia com a natureza. Só são natureza!

Foi possível detectar que a visão de natureza ou percepção é muito mais vivida que descrita verbalmente, indo de encontro ao pensamento de Heisenberg (2009), ao discutir a noção de que há fatos ou fenômenos que a linguagem não dá conta de explicar, que há fatos indescritíveis. Ordenáveis sim, mas para isso torna-se necessário abarcar outros fios, outras leituras de mundo dessa emaranhada teia que forma as interligações da natureza.

A valorização e o fortalecimento da ideia de ecologia integral e identidade terrena são emergentes das sociedades para a conservação e preservação de sua natureza exterior; não se preserva somente a natureza como recurso natural, mas a natureza da humanidade também nesse processo.

A lógica científica, ao excluir esta forma de saber, perde em entendimento e ordenação de fenômenos. As ciências nascem desse saber primitivo que acompanha a humanidade desde o início de sua jornada terrena, que se expressam nos saberes da tradição, obedecendo a um processo de evolução da racionalização humana.

Toda a discussão, que aqui se manifesta não exclui os saberes estabelecidos na ciência moderna, mas integra outros eixos do pensamento para ir de encontro com a multimensionalidade da natureza humana e da natureza da complexidade, fazendo surgir outra consciência de natureza, aquela que se reflete de forma integral, abarcando em si as diversas leituras de mundo e não as excluindo pela pressão da hegemonia social, que se estabeleceu ao longo do tempo, as demais leituras de mundo. 


\section{Referências}

AGUIAR, Maria Ivanilda de; MAIA, Stoecio Malta Ferreira; OLIVEIRA, Teógenes Senna de; MENDONÇA, Eduardo Sá; ARAUJO FILHO, João Ambrósio. Perdas de solo, água e nutrientes em sistemas agroflorestais no município de Sobral, CE. Revista Ciência Agronômica, v.37, n.3, p.270-278, 2006.

ALVIM, Ronaldo Alves Gomes. Ecologia Humana: da Visão Acadêmica aos Temas Atuais. Maceió: Editora EDUFAL, 2012.

ALMEIDA, Maria da Conceição. Complexidade, saberes científicos, saberes da tradição. 2. ed. Revisada e ampliada, São Paulo: Editora Livraria da Física, 2017.

BAPTISTA, Naidison de Quintela; CAMPOS, Carlos Humberto. Educação contextualizada no semiárido. In: IRIOCONTI, Irio Luiz; SCHOREDER, Edni Oscar (orgs). Convivência com o Semiárido Brasileiro: autonomia e protagonismo social. Brasília: 26 Editora IABS, 2013.

BOFF, Leonardo. Saber cuidar: ética do humano-compaixão pela terra. Petrópolis (RJ): Editora Vozes; 1999.

BOHM, David. A totalidade e a ordem implicada: uma nova percepção da realidade. São Paulo: Editora Madras, 2008.

BOMFIM, Luciano Sergio Ventin. No Brasil, a Ecologia Humana é um paradigma científico ou outro tipo de ciência emergente? Revista Ecologias Humanas, v. 2, n. 2, p. 99-122, 2016.

DELEUZE, Gilles; GUATARRI, Félix. O que é filosofia? - Tradução de Bento Prado Jr. E Alberto Alonso Muñoz. 3. ed. São Paulo: Editora 34, 2010.

FEAB, (Federação dos Estudantes de Agronomia do Brasil). Estágios Interdisciplinares de Vivência. Santa Maria: Núcleo de Trabalho Permanente em Movimentos Sociais, p. 57, 2005.

GUALDEZ, Jean Michel da Silva; SILVA, Rosicléia da; BRITO, Aline Dias;

CARVALHO, Carlos Anderson Sousa de; BATISTA, Maria Grings. A descoberta de outra realidade: uma experiência no Assentamento Benedito Alves Bandeira (BAB) no Município do Acará, Pará. Cadernos de Agroecologia - ISSN 2236-7934 - Anais. VI CLAA, X CBA e V SEMDF, v. 13, n. 1, jul. 2018.

HEISENBERG, Werner Karl. A parte e o todo: Encontros e conversas sobre física, filosofia, religião e política. Rio de Janeiro: Editora Contraponto, 1996.

HEISENBERG, Werner Karl. A ordenação da realidade. Traduzido por Marcos Antônio Casanova. Rio de Janeiro: Editora Forense universitária, 2009.

LARROSA, Jorge. Experiência e alteridade em educação. Revista Reflexão e Ação, v. 19, n. 2, p. 04-27, 2011. 
LOUREIRO, Carlos Frederico; LAYRARGUES, Philippe Pomier. Ecologia política, justiça e educação ambiental crítica: perspectivas de Aliança contra hegemônica. Trab. Educ. Saúde, Rio de Janeiro, v. 11, n. 1, p. 53-71, jan./abr., 2013.

MARQUES, Juracy. (2014). Ecologias Humanas. Feira de Santana: Editora Universidade Estadual de Feira de Santana, 2014.

MORIN, Edgar. O método 3: Conhecimento do conhecimento. Edgar Morin; Tradução Juremir Machado da Silva. 5 ed. Porto Alegre: Editora Sulina, 2015.

MORIN, Edgar; CIURANA, Emilio-Roger; DOMINGO, Raúl Motta. Educar na era planetária: o pensamento complexo como método de aprendizagem no erro e na incerteza humana. São Paulo: Editora Cortez, 2003.

MORIN, Edgar. Os sete saberes necessários à educação do futuro. 2. ed. São Paulo: Editora Cortez; Brasília: UNESCO, 2000.

MIRA, Feliciano José Borralho de; AMÂNCIO, Wellington da Silva; ANDRADE, Maria José Gomes de. A Ecologia Humana e as gentes do sertão nordestino. In: SANTOS, Carlos Alberto B. dos; NOGUEIRA, Eliane Maria de Souza; ANDRADE, Maria José Gomes de; ANDRADE, Wbaneide Martins de (Orgs). Os saberes populares no viés da Ecologia Humana. Paulo Afonso: Editora Sociedade Brasileira de Ecologia Humana, 2016.

PORTO-GONÇALVES, Carlos Walter. A globalização da natureza e a natureza da globalização. Rio de Janeiro: Editora Civilização Brasileira, 2006.

RAMOS, Graciliano. Vidas Secas. Rio de Janeiro: Editora Record, 74. ed, 1998.

SILVA, Francisco Lucas da. Um sábio na natureza. ALMEIDA, Maria da Conceição; SEVERO, Thiago Emmanuel Araújo (Orgs.). Natal: Editora IFRN, 2015.

SILVA, Ioná Pereira da; BOMFIM, Luciano Sergio Ventin. O Télos da Ecologia Humana no Brasil e sua interface com as populações tradicionais. Acta Brasiliensis, v. 3, n. 1, p. 35-39, 2019.

VERGANE, Tereza. Matemática e linguagem (s): Olhares interativos e transculturais. Lisboa: Editora Pandora, 2002.

YIN, Robert K. Estudo de caso: planejamento e métodos. 3. ed. Tradução de Daniel Grassi. Porto Alegre: Editora Bookmann, 2005.

Submetido em: 03-07-2020.

Publicado em: 18-12-2020. 